\title{
A Review: Matrix Metallopeptidase-9 Nanoparticles Targeted for the Treatment of Diabetic Foot Ulcers
}

\author{
Wakuma Wakene Jifar (1D' \\ Seyfe Asrade Atnafie (iD ${ }^{2}$ \\ Sundaramoorthy \\ Angalaparameswari ${ }^{\prime}$ \\ 'Mettu University, College of Health \\ Sciences, Department of Pharmacy, \\ Mettu, Ethiopia; ${ }^{2}$ University of Gondar, \\ College of Medicine and Health Sciences, \\ School of Pharmacy, Department of \\ Pharmacology, Gondar, Ethiopia
}

\begin{abstract}
Diabetes foot ulcers are a leading cause of death in diabetic individuals. There are very few medicines and treatments that have received regulatory clearance for this indication, and numerous compounds from various pharmacological classes are now in various stages of clinical studies for diabetic foot ulcers treatment. Multiple risk factors contribute to diabetic foot ulcers, including neuropathy, peripheral artery disease, infection, gender, cigarette smoking, and age. The present difficulties in diabetic foot ulcers treatment are related to bacterial resistance to currently utilized antibiotics. Inhibition of the quorum sensing (QS) system and targeting matrix metallopeptidase-9 (MMP-9) are promising. This study focuses on the difficulties of existing treatment, current treatment technique, and novel pharmacological targets for diabetic foot ulcer. The electronic data base search diabetic for literature on foot ulcers treatment was carried out using Science Direct, PubMed, Google-Scholar, Springer Link, Scopus, and Wiley up to 2021. Becaplermin, a medication that targets MMP-9, glyceryl trinitrate, which inhibits the bacterial quorum sensing system, probiotic therapy, and nano technological solutions are just a few of the novel pharmaceuticals being developed for diabetic foot ulcers treatment. A combination of therapies, rather than one particular agent, will be the best option for treatment of Diabetes foot ulcer since it is multifactorial factors that render occurs of diabetic foot ulcer.
\end{abstract}

Keywords: diabetic foot ulcer, gangrene, probiotics, antimicrobial peptide

\section{Introduction}

Diabetes mellitus (DM) is a long-term metabolic disorder characterized by hyperglycemia. ${ }^{1}$ According to the World Health Organization's global diabetes report, ${ }^{2}$ the global prevalence of diabetes was 422 million in 2014, with the highest trend in the Eastern Mediterranean region, increasing from 5.9\% in 1980 to $13.7 \%$ in 2014, with the global prevalence expected to creep up to 592 million by 20,353 . The World Health Organization defines diabetic foot (DF) as

the foot of a diabetic patient that has the potential risk of pathologic consequences including infection, ulceration, and/or destruction of deep tissues associated with neurologic abnormalities, various degrees of peripheral vascular disease, and/or metabolic complications of diabetes in the lower limb. ${ }^{2}$

Early identification of the at-risk foot should be given high clinical priority in order to avoid the development of foot ulcers. ${ }^{3}$

\section{Epidemiology}

Zhang et al found that Belgium has the greatest prevalence internationally in a recent systematic review and meta-analysis of data from various continents 
$(16.6 \%)^{4}$ The global prevalence of DFU was $6.3 \%$, with type 2 diabetes having a greater prevalence $(6.4 \%)$ than type 1 diabetes $(5.5 \%)$. Belgium has the highest prevalence $(14.8 \%)$, followed by Canada and the United States $(13.0 \%)$. North America has the greatest continental prevalence $(13 \%)$ of any continent. Africa accounted for $7.2 \%$, Asia for 5.5\%, and Europe for 5.1\%. ${ }^{5}$ According to study by Degu et al, in Ethiopia the prevalence of diabetic foot ulcers in Addis Ababa, Jimma, Gondar, Bahir dar, Mekele, Arba Minch, and Dessie, is 1.36\%, $25.76 \%, 13.62 \%, 21.22 \%, 12.28 \%, 14.87 \%$ and $1.85 \%$ respectively. ${ }^{6}$

In addition, studies by Mariam et al at the University of Gondar Referral Hospital on the Prevalence of Diabetic Foot Ulcer and Associated Factors among Adult Diabetic Patients who attend the Diabetic Follow-Up Clinic showed the same results $(13.6 \%){ }^{7}$ Non-healing foot ulcers are the cause of about $85 \%$ of lower extremity amputations. A diabetic person's lifetime risk of having a foot ulcer might be as high as $25 \%$. Lower limb amputations are 15 times more common in diabetes individuals than in nondiabetics. $^{8}$

\section{Etiology and Risk Factors}

DFUs are caused by a number of interconnected causes, the most frequent of which are peripheral neuropathy and Peripheral Arterial Disease (PAD). As a result, DFUs are often categorized as neuropathic, neuroischaemic, or ischaemic ulcers. Since the 1990s, the prevalence of neuroischaemic and ischaemic ulcers has increased from about one-third of patients to become the most prevalent aetiology of DFUs. ${ }^{9,10}$ This is most likely owing to increasing knowledge of the significance of ischaemia in DFUs and their negative consequences, however it might also be due to improved diagnostic techniques, which has implications for diagnostic criteria recommendations. ${ }^{10,11}$ During diagnosis, $70-83 \%$ of diabetes patients with severe soft-tissue infections are polymicrobial. ${ }^{12}$ Furthermore, as compared to acute wounds, chronic DFUs have unusually high Matrix metalloprotease (MMP) levels, which promotes tissue degradation and eventually hinders normal healing processes. ${ }^{13}$

\section{Gangrene in Diabetics}

Diabetes and long-term smoking both raise the risk of gangrene. ${ }^{14}$ Gas gangrene, a rare consequence of diabetic foot ulcers, can occur in people with these persistent non-healing lesions. ${ }^{15}$ Gangrene is produced by a reduction in blood flow to the afflicted tissues, which results in cell death owing to a hypoxic environment and cellular damage caused by Advanced Glycation End Products. $^{16}$

\section{Wound Healing Process in Diabetes Mellitus and in Normal Wound \\ Healing}

In healthy people, wound closure consists of several sequential processes: rapid hemostasis, which involves platelet aggregation to form the platelet plug; inflammation, which involves neutrophils, Macrophages, and mast cells releasing proinflammatory cytokines; and wound contraction, which occurs when inflammation decreases, angiogenesis occurs, keratinocytes and fibroblasts migrate, and wound contraction occurs. ${ }^{17,18}$

Diabetes mellitus (DM) affects wound closure processes, beginning with a reduction in fibrinolysis and an imbalance of cytokines, which produces a change in wound closure. ${ }^{18}$ Hyperglycemia also limits angiogenesis and cell migration, resulting in inadequate reepithelialization; similarly, fibroblasts' poor synthesis of extracellular matrix (ECM) contributes to the problem of insufficient wound healing. ${ }^{19,20}$

During wound-induced hypoxia, vascular endothelial growth factor released by macrophages, fibroblasts, and epithelial cells phosphorylates and activates endothelial nitric oxide synthase in the bone marrow, resulting in an increase in NO levels and the mobilization of bone marrow EPCs to the circulation. SDF-1a, a chemokine, increases EPC homing to the site of damage, where they engage in neovasculogenesis. Gallagher et $\mathrm{al}^{20}$ demonstrate that in a diabetic mouse model (right), eNOS phosphorylation in the bone marrow is reduced, limiting EPC mobilization from the bone marrow into the circulation. They also reveal that SDF-1a expression is reduced in diabetic wound epithelial cells and my fibroblasts, which inhibits EPC homing to wounds and hence restricts wound healing. The authors go on to show that inducing hyperoxia in wound tissue (through $\mathrm{HBO}$ treatment) activated multiple NOS isoforms, raised NO levels, and improved EPC mobilization to the circulation. These findings imply that HBO treatment coupled with SDF-1a administration might be a promising therapeutic approach for accelerating diabetic wound healing, either alone or in conjunction with established clinical procedures. $^{21-26}$ 


\section{Current Approach to the Diabetic Foot Ulcers Management Wound Dressing}

Before putting a sterile dressing, the wound should be cleaned with an antiseptic solution. Antiseptics have a larger spectrum of activity and various targets, including bacteria, fungus, viruses, and protozoa. ${ }^{27}$ The applications and indications for antiseptics vary; nevertheless, their use as preventive anti-infective agents for open wounds such as lacerations, abrasions, burns, and chronic ulcers has been a source of considerable debate for some years. ${ }^{28}$ Povidoneiodine, chlorhexidine, alcohol, acetate, hydrogen peroxide $(\mathrm{H} 2 \mathrm{O} 2)$, boric acid, silver nitrate, silver sulfadiazine, and salt are the most widely used antiseptic solution items in clinical practice today. In order to facilitate the removal of a dressing, the moisture of the material should be adequate enough to prevent adherence to the surrounding skin. In the case of dry DFUs, the use of hydrogel has been suggested. ${ }^{29,30}$

\section{Antimicrobial Peptides}

Antimicrobial peptides (AMPs) are host defense peptides because they have properties of both the innate and adaptive immune systems, which are found in nearly all species. AMPs are short polypeptides with an amphipathic structure and a cationic property (usually no more than 60 amino acids). Most AMP serve as the initial line of defense against the spread of a wide range of pathogens, including bacteria, fungus, viruses, and protozoan parasites. ${ }^{31-33}$ Most AMPs are now utilized in clinical trials, and they are used to treat a variety of human ailments, including diabetic foot ulcers. For example, the Neuprex medicines (RBPI 21) are designated as orphan medications by the FDA. Despite the fact that the degree of toxicity of Neuprex is unclear, research on a topical route for its administration are being examined. ${ }^{34}$ A recent study of accessible patent information on the therapeutic application of AMPs from 2003 to 2015 showed that the majority of the claimed AMPs were described not only as strong antibiotics, but also as efficient modulators of inflammation or neutralizers of pathogenic toxin. ${ }^{35}$

\section{Phenytoin}

Phenytoin promotes improves healing through several mechanisms, including stimulation of fibroblast proliferation, improvement of granulation tissue formation, reduced collagenase activity, inhibition of glucocorticoid activity, and direct or indirect antibacterial activity via inflammatory cells and neovascularization. ${ }^{36}$

Heparin is extensively praised for its beneficial effects on local tissue microcirculation and oxygenation by inhibiting thrombin production and improving fibrin gel porosity. This greatly promotes fibrinolysis, demonstrating its use in DFUs. Aside from its significant anti-thrombotic benefits, heparin is also reported to be viable in vitro, encouraging heparin sulfate synthesis in endothelial cell cultures. $^{37}$

\section{Growth Factors}

PDGF is a mitogenic bioactive substance that induces the differentiation of undifferentiated mesenchymal cells into mature tissue, resulting in the creation of new cells and an increase in wound healing. Furthermore, platelets have the potential to stimulate tissue migration and angiogenesis from a pre-formed vascular bed, as well as provide vascular endothelial synthesis with a last boost by causing vasodilation. ${ }^{38}$ Defective IGF expression in DM patients' dermal fibroblasts has been demonstrated, and this may be responsible for the delayed wound healing observed in this population. Some wound healing therapies continue to target variables that promote tissue IGF. ${ }^{39}$

\section{Anti-Diabetic Drugs and Diabetic Foot Ulcers}

Insulin

Maintaining normoglycemia with adequate food and/or anti-diabetic medications is one of the most effective strategies of preventing diabetes complications. Insulin intravenous injection was observed to improve DFU healing at a reported healing rate of $30.3 \%{ }^{40}$ It is referred to as a physiological glucose-lowering agent. The use of dermal insulin administration as a healing agent in DFUs has lately been a source of concern. ${ }^{41,42}$

\section{Dipeptidyl Peptidase-4 (DPP-4) Inhibitors}

DPP-4 is a large-scale enzyme that causes the inactivation of GLP-1 and GIP cretin hormones. In T2DM, ${ }^{43}$ DPP-4 inhibitors are oral medications authorized by FDA which block dipeptidyl peptidase and improve the flow of incrinated hormones while providing glycemic control and enhanced cell activity of islet. DPP-4 inhibitors, such as sitagliptin, vildagliptin, and anagliptin, are used to treat diabetes by lowering blood glucose levels. Some medicines, such as Exendin-4, are glucagon-like peptide-1 (GLP-1) receptor agonists produced from the saliva of 
the Gila monster, a huge poisonous lizard located in the United States' South Western area; it is dermal application of this drug expedited DFU wound healing in experimental animals with or without the addition of adipose-derived stem cells. ${ }^{44,45}$

\section{Use of Enzymes in Diabetic Foot Ulcers}

Urokinase, also known as Urokinase-type plasminogen activator (uPA), is a serine protease that is released and produced by keratinocyte cells. Mostly expressed during wound healing by migrating keratinocytes. ${ }^{10,46}$ Patients with DFU showed rapid improvement in clinical signs and symptoms following a continuous, 96-hour infusion of Urokinase via the femoral artery, according to a limited trial of 6 patients. This can be attributed to the restoration of collateral blood flow in and around the site. ${ }^{47}$

\section{Use of Stem Cells in Diabetic Foot Ulcer}

Stem cells such as adipose-derived stem cells and endothelian progenitors cells imported from bone marrow or other sources can generate blood vessel and extracellular matrix cell precursors in DFUs. ${ }^{48,49}$ These progenitor cells can be implanted into the wound to stimulate the creation of new cells in the wound region. ${ }^{50}$

\section{Natural Products}

Several investigations reported the benefits of plants, such as Aloe vera, Salvia miltiorrhiza, Mimosa tenuiflora, Alchemilla vulgaris, Angelica sinensis, and Moringa oleifera which are used in a wide range of cosmetic products, such as ointments, creams, and gels. Moringa oleifera has been shown to reduce DFU wound size, improve tissue granulation, and significantly reduce the levels of a multitude of cytokines including, but not limited to, TNF- $\alpha$, IL- 6 and VEGF. ${ }^{51,52}$

Honey contains antibacterial, antioxidant, and antiinflammatory properties that help to cure wounds and burns while causing no harm. In recent years, therapy with honey has sparked considerable interest as an alternative treatment for DFUs, with several research evaluating various characteristics of honey to treat DFUs at various stages. ${ }^{53,54} \mathrm{~A}$ recent study compared honey dressings to conventional saline solution dressings and discovered that honey dressings were more efficient in terms of healing time and number of wounds cured after 120 days. ${ }^{55}$

\section{Challenges to Current Treatment for Diabetic Foot Ulcer}

The primary treatment problems associated with DFU are believed to be diabetic foot infections and delayed wound healing. ${ }^{56}$ Because probiotics have the capacity to boost the immune system, have anti-inflammatory properties, and therefore might accelerate the wound healing process, the concept of probiotic consumption is fascinating and important in light of the rising worldwide antimicrobial drug resistance concerns. ${ }^{57,58}$ According to $\mathrm{WHO}, 60 \%$ of bacteria are becoming resistant to key antibiotics, and in the next years, all diseases will acquire $100 \%$ drug resistance. One explanation for greater adaptability of bacteria to antibiotics may be self-medication as well as continuous administration. Rigorous research operations are continuing to discover other means of treating illnesses caused by these microbes. ${ }^{59}$ A new method, such as probiotics and phage treatment, can remove harmful microorganisms and perhaps enhance the healing process. ${ }^{60}$

\section{Bacteriophages}

Bacteriophages are viruses that identify and reproduce in bacterial cells. Bacteriophages contain capsid protein heads that transport and protect the virus's genetic material. ${ }^{61}$ Depending on the virus, the genetic material can vary in size, organization (circular, linear, or segmented), and structure (ssDNA, dsDNA, ssRNA, dsRNA). Bacteriophages are very host specific and will only attack particular strains based on the bacteriophage utilized and the target proteins that aid in bacterial host attachment. ${ }^{62}$ So far, phages have been shown to be effective in treating bacterial diseases such as cerebrospinal meningitis, skin infections caused by $\mathrm{P}$. aeruginosa, S. aureus, K. pneumoniae, and E. coli, among others, as well as cystic fibrosis, eye infections, neonatal sepsis, urinary tract diseases, and cancers. ${ }^{63}$ According to Khalifa et al, the Myoviridae bacteriophage EFLK1 was effectively identified against the phage-resistant strain of Vancomycin-resistant Enterococcus faecalis V583. ${ }^{64,65}$ Because of genetic supremacy, even phage resistant bacteria can be destroyed by other phages from the same host in this research. Ryan et al suggested that bacteriophage T4 and antibiotic cefotaxime combined therapy can eradicate the biofilms of $E$. coli and even alone phage therapy can clear the E. coli biofilm. 


\section{Probiotics Therapy}

Probiotics are among these new agents which are widely used and extensively studied for their health promoting effects. ${ }^{66}$ Probiotics are either a single strain or a combination of various organisms, and they are capable of strengthening immune systems, producing antiinflammatory activity and improving wound healing following inflammatory cell buildup at the wound site. ${ }^{67}$ Recent randomized controlled trials experiments have demonstrated that certain intestinal bacteria, like Lactobacillus and Bifidobacteria, inhibit cariogenic streptococci and Candida Spp, have positive effects in their oral action. $^{68}$

\section{Amputation}

Amputation above the ankle is frequently a problem or need for a patient with infected DFUs and PAD. The fiveyear death rate following a diabetes-related amputation is up to $60 \%$, which is greater than the mortality rate for some cancers. 68. Patients at high risk for ulceration and those who have had an amputation for a DFU should be evaluated by a DFU expert team one to three times each month. At each visit, the patients' feet should be examined, and the need for a vascular assessment should be determined. ${ }^{69}$

\section{New Drug Targets for Diabetic Foot Ulcer}

Inhibition of quorum sensing system for Treating Chronic Wounds.

\section{Role of Quorum Sensing (QS) Mechanism in Inhibiting Wound Healing}

The QS-System is a two-component system composed of an enzyme that catalyzes the signal molecule (auto inducer) synthesis reaction and a receptor molecule that binds to the signal molecule (for example, acyl-homoserine lactone, AHL, and cyclic peptides) and regulates the transcription of many genes in addition to that encoding the signal molecule. ${ }^{70}$

Because the bacterial QS system is required for biofilm development in chronic wounds, it is an important target for anti-biofilm treatment. Because the QS system is reliant on signaling by auto inducer chemicals, blocking these would prevent coordinated virulence action. Gram-positive and Gram-negative bacteria have a wide range of QS systems. $^{71}$ The capacity of glyceryl trinitrate (GTN) to suppress QS-based biofilm development in P. aeruginosa burn infections was investigated. ${ }^{72}$ GTN is a wound healing and antibacterial agent that has been authorized by the FDA. It is used in ointments for treating anal fissures and for inhibiting plank tonic Candida albicans when used at a concentration $0.15 \%$ to $0.3 \%$. GTN was found to inhibit biofilm formation by P. aeruginosa. ${ }^{73,74}$

\section{Targeting Matrix Metallopeptidase 9 (MMP-9) in Diabetic Foot Ulcers}

Wound healing can be hampered by stress. Cortisol, a steroid hormone, is increased during stress and chronic inflammation, and it slows wound healing. ${ }^{75}$ Elevated MMP-9 levels have been linked to higher cortisol levels in individuals with coronary artery disease. Prostaglandin E2 has been shown to increase cortisol release and to activate MMP-9. The increased activity of matrix metalloproteinase (MMPs) ${ }^{76}$ is one of the culprits in the recalcitrance. MMPs are categorized in several ways, including their preferred substrates, such as gelatinases (MMP-2 and MMP-9), collagenases (MMP-1, MMP-8, and MMP-13), and stromelysins (MMP-3 and MMP-10). The first generation of MMPIs were broad-spectrum zinc chelators with low bioavailability, prompting the development of a second generation of orally bioactive broad-spectrum inhibitors. The medication becaplermin Gelatinase activity was reduced, but collagenase activity was unaffected; active MMP-9 was reduced, while active MMP-8 was unaffected. ${ }^{77}$

Treatments for DFUs that do not specifically target MMPs can have important effects on MMP expression and activity. As MMP-9 has long been of interest in wound healing, most studies have focused on the effects on this proteinase in particular (Table 1).

\section{Nano Biotechnology Solutions for Wound Healing and Healing Diabetic Wounds}

Debridement was not performed with Nano scale treatments. Pectins found in hibiscus flowers bond to heavy metal ions. Heavy metal ions have a strong affinity for these pectins. Some red spinach extracts can be utilized for heavy metal and toxic metabolite bio-chelation because they have an unusual structure that binds harmful species. ${ }^{85}$ The particle sizes of the bioactive forms produced from the extracts range from $35 \mathrm{~nm}$ to $200 \mathrm{~nm}$, with a peak at $100 \mathrm{~nm} .{ }^{86}$ 
Table I Summary of the Matrix Metalloproteinase-9 Treatment Articles That Were Previously Published and Included Studies in the Review, 2021

\begin{tabular}{|c|c|c|c|c|}
\hline Treatment & Study Material & Method of MMP Measuring & Effect on MMPs & Reference \\
\hline $\begin{array}{l}\text { Vacuum-assisted } \\
\text { closure (VAC) }\end{array}$ & $\begin{array}{l}\text { Human chronic wound } \\
\text { fluid }\end{array}$ & Gelatin zymography & Reduced MMP-9 and MMP-2 & [78] \\
\hline VAC & $\begin{array}{l}\text { Human chronic wound } \\
\text { fluid }\end{array}$ & ELISA & $\begin{array}{c}\text { Reduced MMP-9/TIMP-I ratio, no change } \\
\text { in MMP-9 }\end{array}$ & [79] \\
\hline $\begin{array}{l}\text { Mesenchymal stem } \\
\text { cells (MSC) }\end{array}$ & $\begin{array}{l}\text { Mouse model of diabetic } \\
\text { wounds }\end{array}$ & $\begin{array}{c}\text { Gelatin zymography, quantitative } \\
\text { PCR }\end{array}$ & Reduced MMP-9 activity and expression & [80] \\
\hline $\mathrm{N}$-acetyl cysteine & $\begin{array}{l}\text { HaCat cells treated with } \\
\text { MGO }\end{array}$ & Western blot & Reduced MMP-9 expression & [8I] \\
\hline $\begin{array}{l}\text { Manuka honey } \\
\text { wound dressing }\end{array}$ & $\begin{array}{l}\text { Human DFU patient } \\
\text { wound fluid }\end{array}$ & ELISA & $\begin{array}{l}\text { Increased MMP-9 expression (no } \\
\text { improvement on ulcer healing) }\end{array}$ & [82] \\
\hline Becaplermin & $\begin{array}{l}\text { Mouse model of diabetic } \\
\text { wounds }\end{array}$ & $\begin{array}{l}\text { In-situ zymography and batimastat } \\
\text { affinity resin coupled proteomics }\end{array}$ & $\begin{array}{c}\text { Decreased gelatinase activity, no effect on } \\
\text { collagenase activity; decreased active MMP- } \\
\text { 9, no effect on active MMP-8 }\end{array}$ & [83] \\
\hline Aclerastide & $\begin{array}{c}\text { Mouse model of diabetic } \\
\text { wounds }\end{array}$ & $\begin{array}{c}\text { Batimastat affinity resin coupled } \\
\text { proteomics }\end{array}$ & $\begin{array}{c}\text { Increased active MMP-9, no effect on active } \\
\text { MMP-8 }\end{array}$ & [84] \\
\hline
\end{tabular}

Abbreviations: ELISA, enzyme-linked immunosorbent assay; DFU, diabetic foot ulcer; MMP-8, matrix metalloproteinase-8; MMP-9, matrix metalloproteinase-9; PCR, polymerase chain reaction; VAC, vacuum-assisted closure; MGO, methylglyoxal; HaCaT, cultured human keratinocyte (cells); THMM-I, tissue inhibitor matrix metalloproteinase-I.

\section{Conclusion}

Diabetic foot ulcer (DFU) is a significant complication of diabetes, complicating the lives of millions of diabetic individuals. Despite the medical community's extensive understanding of DFU, there is still a continuing effort to discover the most appropriate therapy for this debilitating illness; one that is not only cost effective, but also safe to give.

Because DFU is caused by a mix of variables, a combination of treatments, rather than a single drug, will be the best option for therapy. The use of antidiabetic medicines such as insulin, exendin-4, and DPP4 inhibitors holds a lot of promise because this class of treatments targets the source of the problem, hyperglycemia and MMP-9 were observed in mouse and human diabetic wounds using a batimastat affinity resin and proteomics. MMP-9 was shown to play a detrimental role in diabetic wound healing, whereas MMP-8 was beneficial. A new class of selective MMP-9 inhibitors shows clinical promise for the treatment of DFUs. Normal glycemia aids in the correction of the underlying issues that contribute to the formation of DFU, and so serves as both a preventative strategy and a facilitator of wound healing in DFUs.

\section{Author Contributions}

All authors made a significant contribution to the work reported, that is in the conception, study design, execution, acquisition of data, analysis and interpretation, or in all these areas; took part in drafting, revising or critically reviewing the article; gave final approval of the version to be published; have agreed on the journal to which the article has been submitted; and agree to be accountable for all aspects of the work.

\section{Funding}

The author(s) received no financial support for the research, authorship, and/or publication of this article.

\section{Disclosure}

The author(s) declared no potential conflicts of interest with respect to the research, authorship, and/or publication of this article.

\section{References}

1. Ciemins EL, Coon PJ, Fowles JB, Min S-J. Beyond health information technology: critical factors necessary for effective diabetes disease management. J Diabetes Sci Technol. 2009;3(3):452-460. doi:10.1177/ 193229680900300308 
2. Foot IWGotD. International consensus on the diabetic foot and practical guidelines on the management and prevention of the diabetic foot. Amsterdam; 2007. Available from: www.idf.org/bookshop.

3. Revathi V. Risk factors associated with the development of diabetic foot ulcer among adult type 2 diabetes mellitus patients in a secondary care setting in Pathanamthitta district. SCTIMST; 2016.

4. Zhang P, Lu J, Jing Y, Tang S, Zhu D, Bi Y. Global epidemiology of diabetic foot ulceration: a systematic review and meta-analysis. Ann Med. 2017;49(2):106-116. doi:10.1080/07853890.2016.1231932

5. Ibrahim AM. Diabetic foot ulcer: synopsis of the epidemiology and pathophysiology. Int $J$ Diabetes Endocrinol. 2018;3:23. doi:10.11648/j.ijde.20180302.11

6. Degu H, Wondimagegnehu A, Yifru YM, Belachew A. Is health related quality of life influenced by diabetic neuropathic pain among type II diabetes mellitus patients in Ethiopia? PLoS One. 2019;14(2):0211449. doi:10.1371/journal.pone.0211449

7. Mariam TG, Alemayehu A, Tesfaye E, et al. Prevalence of diabetic foot ulcer and associated factors among adult diabetic patients who attend the diabetic follow-up clinic at the University of Gondar Referral Hospital, North West Ethiopia, 2016: institutional-Based Cross-Sectional Study. J Diabetes Res. 2017;2017:1-8. doi:10.1155/ 2017/2879249

8. Krentz A, Acheson P, Basu A, Kilvert A, Wright A, Nattrass M. Morbidity and mortality associated with diabetic foot disease: a 12-month prospective survey of hospital admissions in a single UK centre. Foot. 1997;7(3):144-147. doi:10.1016/S0958-2592(97) 90025-0

9. Abidia A, Laden G, Kuhan G, et al. Multicenter study of the incidence of and predictive risk factors for diabetic neuropathic foot ulceration. Diabetes Care. 1998;21:1071-1075. doi:10.2337/ diacare.21.7.1071

10. Gershater M, Löndahl M, Nyberg P, et al. Complexity of factors related to outcome of neuropathic and neuroischaemic/ischaemic diabetic foot ulcers: a cohort study. Diabetologia. 2009;52 (3):398-407. doi:10.1007/s00125-008-1226-2

11. Lipsky BA, Aragón-Sánchez J, Diggle M, et al. IWGDF guidance on the diagnosis and management of foot infections in persons with diabetes. Diabetes Metab Res Rev. 2016;32:45-74. doi:10.1002/ dmrr.2699

12. Karri VVSR, Kuppusamy G, Talluri SV, Yamjala K, Mannemala SS, Malayandi R. Current and emerging therapies in the management of diabetic foot ulcers. Curr Med Res Opin. 2016;32(3):519-542. doi:10.1185/03007995.2015.1128888

13. Baltzis D, Eleftheriadou I, Veves A. Pathogenesis and treatment of impaired wound healing in diabetes mellitus: new insights. Adv Ther 2014;31(8):817-836. doi:10.1007/s12325-014-0140-x

14. Al Wahbi A. Autoamputation of diabetic toe with dry gangrene: a myth or a fact? Diabetes Metab Syndr Obes. 2018;11:255. doi:10.2147/DMSO.S164199

15. Pichu S, Sathiyamoorthy J, Krishnamoorthy E, Umapathy D, Viswanathan V. Impact of the hypoxia inducible factor-1 $\alpha$ (HIF-1 $\alpha$ ) pro582ser polymorphism and its gene expression on diabetic foot ulcers. Diabetes Res Clin Pract. 2015;109(3):533-540. doi:10.1016/j. diabres.2015.05.014

16. Gary Sibbald R, Woo KY. The biology of chronic foot ulcers in persons with diabetes. Diabetes Metab Res Rev. 2008;24(S1):25S30. doi:10.1002/dmrr.847

17. Moura J, Børsheim E, Carvalho E. The role of micrornas in diabetic complications - special emphasis on wound healing. Genes. 2014;5 (4):926-956. doi:10.3390/genes5040926

18. Theoret C. Physiology of wound healing. In: Equine Wound Management; 2016:1-13.

19. Guo S, DiPietro LA. Factors affecting wound healing. J Dent Res. 2010;89(3):219-229. doi:10.1177/0022034509359125
20. Gallagher K, Liu ZJ, Xiao M, et al. Diabetic impairments in NO-mediated endothelial progenitor cell mobilization and homing are reversed by hyperoxia and SDF-1alpha. $J$ Clin Invest. 2007;117:1249-1259. doi:10.1172/JCI29710

21. Perez-Favila A, Martinez-Fierro ML, Rodriguez-Lazalde JG, et al. Current therapeutic strategies in diabetic foot ulcers. Medicina. 2019;55(11):714. doi:10.3390/medicina55110714

22. Brem H, Tomic-Canic M. Cellular and molecular basis of wound healing in diabetes. J Clin Invest. 2007;117(5):1219-1222. doi:10.1172/JCI32169

23. Hocking AM. The role of chemokines in mesenchymal stem cell homing to wounds. Adv Wound Care. 2015;4(11):623-630. doi:10.1089/wound.2014.0579

24. Abdissa D, Adugna T, Gerema U, Dereje D. Prevalence of Diabetic foot ulcer and associated factors among adult diabetic patients on follow-up clinic at Jimma Medical Center, Southwest Ethiopia, 2019: an Institutional-Based Cross-Sectional Study. $J$ Diabetes Res. 2020;2020. doi:10.1155/2020/4106383

25. Deshpande R, Kanitkar M, Kadam S, et al. Matrix-entrapped cellular secretome rescues diabetes-induced EPC dysfunction and accelerates wound healing in diabetic mice. PLoS One. 2018;13(8):e0202510. doi:10.1371/journal.pone.0202510

26. Galvez MG, Chang EI, Gurtner GC. Endothelial progenitor cell's contribution to wound healing and skin graft neovascularization; 2010.

27. Atiyeh BS, Dibo SA, Hayek SN. Wound cleansing, topical antiseptics and wound healing. Int Wound J. 2009;6(6):420-430. doi:10.1111/ j.1742-481X.2009.00639.x

28. Lipsky BA, Hoey C. Topical antimicrobial therapy for treating chronic wounds. Clin Infect Dis. 2009;49(10):1541-1549. doi: $10.1086 / 644732$

29. Stevens R, Gardner E, Lee S. A simple, effective and cheap device for the safe irrigation of open traumatic wounds. Emerg Med J. 2009;26(5):354-356. doi:10.1136/emj.2007.055343

30. Barua RS, Sy F, Srikanth S, et al. Effects of cigarette smoke exposure on clot dynamics and fibrin structure: an ex vivo investigation. Arterioscler Thromb Vasc Biol. 2010;30(1):75-79. doi:10.1161/ ATVBAHA.109.195024

31. Abbas M, Uckay I, Lipsky BA. In diabetic foot infections antibiotics are to treat infection, not to heal wounds. Expert Opin Pharmacother. 2015;16(6):821-832. doi:10.1517/14656566.2015.1021780

32. Uçkay I, Aragón-Sánchez J, Lew D, Lipsky BA. Diabetic foot infections: what have we learned in the last 30 years? Int J Infect Dis. 2015;40:81-91. doi:10.1016/j.ijid.2015.09.023

33. Ginsburg I, van Heerden PV, Koren E. From amino acids polymers, antimicrobial peptides, and histones, to their possible role in the pathogenesis of septic shock: a historical perspective. J Inflamm Res. 2017;10:7. doi:10.2147/JIR.S126150

34. Reddy K, Yedery R, Aranha C. Antimicrobial peptides: premises and promises. Int J Antimicrob Agents. 2004;24(6):536-547. doi:10.1016/ j.ijantimicag.2004.09.005

35. Jin G, Weinberg A. Human antimicrobial peptides and cancer. Semin Cell Dev Biol. 2019;88:156-162. Elsevier. doi:10.1016/j. semcdb.2018.04.006

36. Nader HB, Buonassisi V, Colburn P, Dietrich CP. Heparin stimulates the synthesis and modifies the sulfation pattern of heparan sulfate proteoglycan from endothelial cells. J Cell Physiol. 1989;140 (2):305-310. doi:10.1002/jcp.1041400216

37. Jörneskog G, Brismar K, Fagrell B. Low molecular weight heparin seems to improve local capillary circulation and healing of chronic foot ulcers in diabetic patients. VASA Zeitschrift fur Gefasskrankheiten. 1993;22(2):137.

38. Ma C, Hernandez MA, Kirkpatrick VE, Liang L-J, Nouvong AL, Gordon II. Topical platelet-derived growth factor vs placebo therapy of diabetic foot ulcers offloaded with windowed casts: a randomized, controlled trial. Wounds. 2015;27(4):83-91. 
39. Fan H, Yu J, Cui G, Zhang W, Yang X, Dong Q. Insulin pump for the treatment of diabetes in combination with ulcerative foot infections. J Biol Regul Homeost Agents. 2016;30(2):465-470.

40. Adeghate J, Nurulain S, Tekes K, Fehér E, Kalász H, Adeghate E. Novel biological therapies for the treatment of diabetic foot ulcers. Expert Opin Biol Ther. 2017;17(8):979-987. doi:10.1080/ 14712598.2017.1333596

41. Lima MH, Caricilli AM, de Abreu LL, et al. Topical insulin accelerates wound healing in diabetes by enhancing the AKT and ERK pathways: a double-blind placebo-controlled clinical trial. PLoS One. 2012;7(5):e36974. doi:10.1371/journal.pone.0036974

42. Öhnstedt E, Lofton Tomenius $\mathrm{H}$, Vågesjö E, Phillipson $M$. The discovery and development of topical medicines for wound healing. Expert Opin Drug Discov. 2019;14(5):485-497. doi:10.1080/ 17460441.2019.1588879

43. Matteucci E, Giampietro O. Dipeptidyl peptidase-4 (CD26): knowing the function before inhibiting the enzyme. Curr Med Chem. 2009;16 (23):2943-2951. doi:10.2174/092986709788803114

44. Seo E, Lim JS, Jun J-B, Choi W, Hong I-S, Jun H-S. Exendin-4 in combination with adipose-derived stem cells promotes angiogenesis and improves diabetic wound healing. J Transl Med. 2017;15(1):1-9. doi:10.1186/s12967-017-1145-4

45. Clark GC, Casewell NR, Elliott CT, et al. Friends or foes? Emerging impacts of biological toxins. Trends Biochem Sci. 2019;44 (4):365-379. doi:10.1016/j.tibs.2018.12.004

46. Sun T. Role of plasminogen activator inhibitor-1 (PAI-1) in endothelial senescence and cardiovascular aging. Northwestern University; 2020.

47. Vannini P, Ciavarella A, Mustacchio A, Rossi C. Intra-arterial urokinase infusion in diabetic patients with rapidly progressive ischemic foot lesions. Diabetes Care. 1991;14(10):925-927. doi:10.2337/ diacare.14.10.925

48. Blumberg SN, Berger A, Hwang L, Pastar I, Warren SM, Chen W. The role of stem cells in the treatment of diabetic foot ulcers. Diabetes Res Clin Pract. 2012;96(1):1-9. doi:10.1016/j. diabres.2011.10.032

49. Owczarczyk-Saczonek A, Wociór A, Placek W, Maksymowicz W, Wojtkiewicz J. The use of adipose-derived stem cells in selected skin diseases (Vitiligo, Alopecia, and Nonhealing Wounds). Stem Cells Int. 2017;2017:1-11. doi:10.1155/2017/4740709

50. Qin H, Zhu X, Zhang B, Zhou L, Wang W. Clinical evaluation of human umbilical cord mesenchymal stem cell transplantation after angioplasty for diabetic foot. Exp Clin Endocrinol Diabetes. 2016;124(08):497-503. doi:10.1055/s-0042-103684

51. Muhammad AA, Arulselvan P, Cheah PS, Abas F, Fakurazi S. Evaluation of wound healing properties of bioactive aqueous fraction from Moringa oleifera Lam on experimentally induced diabetic animal model. Drug Des Devel Ther. 2016;10:1715. doi:10.2147/DDDT.S96968

52. Chin C-Y, Ng P-Y, Ng S-F. Moringa oleifera standardised aqueous leaf extract-loaded hydrocolloid film dressing: in vivo dermal safety and wound healing evaluation in STZ/HFD diabetic rat model. Drug Deliv Transl Res. 2019;9(2):453-468. doi:10.1007/s13346-018-0510-z

53. Ramirez-Acuña JM, Cardenas-Cadena SA, Marquez-Salas PA, et al. Diabetic foot ulcers: current advances in antimicrobial therapies and emerging treatments. Antibiotics. 2019;8(4):193. doi:10.3390/ antibiotics 8040193

54. Azzini E, Giacometti J, Russo GL. Antioxidant phytochemicals at the pharma-nutrition interface. Oxid Med Cell Longev. 2017;2017:1-3. doi: $10.1155 / 2017 / 6986143$

55. Jull AB, Cullum N, Dumville JC, Westby MJ, Deshpande S, Walker N. Honey as a topical treatment for wounds. Cochrane Database Syst Rev. 2015;3. doi:10.1002/14651858.CD005083.pub4

56. Sekhar MS, Unnikrishnan M, Vijayanarayana K, Rodrigues GS, Mukhopadhyay C. Topical application/formulation of probiotics: will it be a novel treatment approach for diabetic foot ulcer? Med Hypotheses. 2014;82(1):86-88. doi:10.1016/j.mehy.2013.11.013
57. Oelschlaeger TA. Mechanisms of probiotic actions-a review. Int J Med Microbiol. 2010;300(1):57-62. doi:10.1016/j.ijmm.20 09.08 .005

58. Mohseni S, Bayani M, Bahmani F, et al. The beneficial effects of probiotic administration on wound healing and metabolic status in patients with diabetic foot ulcer: a randomized, double-blind, placebo-controlled trial. Diabetes Metab Res Rev. 2018;34(3):e2970. doi:10.1002/dmrr.2970

59. Bank W. Pulling together to beat superbugs knowledge and implementation gaps in addressing antimicrobial resistance. World Bank; 2019.

60. Brüssow H, Hendrix RW. Phage genomics: small is beautiful. Cell. 2002;108(1):13-16. doi:10.1016/S0092-8674(01)00637-7

61. Salmond GP, Fineran PC. A century of the phage: past, present and future. Nat Rev Microbiol. 2015;13(12):777-786. doi:10.1038/ nrmicro3564

62. Reindel R, Fiore CR. Phage Therapy: Considerations and Challenges for Development. Oxford University Press US; 2017.

63. Oliveira A, Sousa JC, Silva AC, Melo LD, Sillankorva S. Chestnut honey and bacteriophage application to control Pseudomonas aeruginosa and Escherichia coli biofilms: evaluation in an ex vivo wound model. Front Microbiol. 2018;9:1725. doi:10.3389/fmicb.2018.01725

64. Gelman D, Beyth S, Lerer V, et al. Combined bacteriophages and antibiotics as an efficient therapy against VRE Enterococcus faecalis in a mouse model. Res Microbiol. 2018;169(9):531-539. doi:10.1016/j.resmic.2018.04.008

65. Romero J, Higuera G, Gajardo F, et al. Complete genome sequence of Vibrio anguillarum phage CHOED successfully used for phage therapy in aquaculture. Genome Announc. 2014;2(4). doi:10.1128/ genomeA.00091-14

66. Hidalgo-Cantabrana C, Delgado S, Ruiz L, Ruas-Madiedo P, Sánchez B, Margolles A. Bifidobacteria and their health-promoting effects. In: Bugs as Drugs: Therapeutic Microbes for the Prevention and Treatment of Disease; 2018:73-98.

67. Lew LC, Liong MT. Bioactives from probiotics for dermal health: functions and benefits. J Appl Microbiol. 2013;114(5):1241-1253. doi:10.1111/jam.12137

68. Malyar NM, Freisinger E, Meyborg M, et al. Amputations and mortality in in-hospital treated patients with peripheral artery disease and diabetic foot syndrome. J Diabetes Complications. 2016;30 (6):1117-1122. doi:10.1016/j.jdiacomp.2016.03.033

69. Mavrogenis AF, Megaloikonomos PD, Antoniadou T, et al. Current concepts for the evaluation and management of diabetic foot ulcers. EFORT Open Rev. 2018;3(9):513-525. doi:10.1302/2058-5241.3.180010

70. Brackman G, Coenye T. Quorum sensing inhibitors as anti-biofilm agents. Curr Pharm Des. 2015;21(1):5-11. doi:10.2174/ 1381612820666140905114627

71. Abbas HA, Shaldam MA. Glyceryl trinitrate is a novel inhibitor of quorum sensing in Pseudomonas aeruginosa. Afr Health Sci. 2016;16 (4):1109-1117. doi:10.4314/ahs.v16i4.29

72. Das L, Singh Y. Quorum sensing inhibition: a target for treating chronic wounds. In: Biotechnological Applications of Quorum Sensing Inhibitors: Springer; 2018:111-126.

73. Lazaro J, Izzo V, Meaume S, Davies A, Lobmann R, Uccioli L. Elevated levels of matrix metalloproteinases and chronic wound healing: an updated review of clinical evidence. $J$ Wound Care. 2016;25(5):277-287. doi:10.12968/jowc.2016.25.5.277

74. Yousif A, Jamal MA, Raad I. Biofilm-based central line-associated bloodstream infections. In: Biofilm-Based Healthcare-Associated Infections; 2015:157-179.

75. Stojadinovic O, Gordon KA, Lebrun E, Tomic-Canic M. Stressinduced hormones cortisol and epinephrine impair wound epithelization. Adv Wound Care. 2012;1(1):29-35.

76. Jones JI, Nguyen TT, Peng Z, Chang M. Targeting MMP-9 in diabetic foot ulcers. Pharmaceuticals. 2019;12(2):79. doi:10.3390/ ph12020079 
77. Hariono M, Yuliani SH, Istyastono EP, Riswanto FD, Adhipandito CF. Matrix metalloproteinase 9 (MMP9) in wound healing of diabetic foot ulcer: molecular target and structure-based drug design. Wound Med. 2018;22:1-13. doi:10.1016/j.wndm.2018.05.003

78. Greene AK, Puder M, Roy R, et al. Micro deformational wound therapy: effects on angiogenesis and matrix metalloproteinases in chronic wounds of 3 debilitated patients. Ann Plast Surg. 2006;56:418-422. doi:10.1097/01.sap.0000202831.43294.02

79. Mouës CM, Van Toorenenbergen AW, Heule F, Hop WC, Hovius SER. The role of topical negative pressure in wound repair: expression of biochemical markers in wound fluid during wound healing. Wound Repair Regen. 2008;16:488-494. doi:10.1111/ j.1524-475X.2008.00395.x

80. $\mathrm{Xu} \mathrm{J,} \mathrm{Zgheib} \mathrm{C,} \mathrm{Hodges} \mathrm{MM,} \mathrm{Caskey} \mathrm{RC,} \mathrm{Hu} \mathrm{J,} \mathrm{Liechty} \mathrm{KW.}$ Mesenchymal stem cells correct impaired diabetic wound healing by decreasing ECM proteolysis. Physiol Genom. 2017;49:541-548. doi:10.1152/physiolgenomics.00090.2016

81. Yang C, Meng F, Chen L, et al. Inhibition of methylglyoxal-induced AGEs/RAGE expression contributes to dermal protection by N-acetyl-L-cysteine. Cell Physiol Biochem. 2017;41:742-754. doi:10.1159/000458734
82. Tsang -K-K, Kwong EW-Y, To T-S-S, Chung JW-Y, Wong TK-S. A pilot randomized, controlled study of nanocrystalline silver, Manuka honey, and conventional dressing in healing diabetic foot ulcer. Evid Based Complement Alternat Med. 2017;2017:15. doi:10.1155/2017/5294890

83. Nguyen TT, Ding D, Wolter WR, et al. Validation of matrix metalloproteinase-9 (MMP-9) as a novel target for treatment of diabetic foot ulcers in humans and discovery of a potent and selective small-molecule MMP-9 inhibitor that accelerates healing. $J$ Med Chem. 2018;61:8825-8837. doi:10.1021/acs.jmedchem.8b01005

84. Nguyen TT, Ding D, Wolter WR, et al. Expression of active matrix metalloproteinase-9 as a likely contributor to the clinical failure of aclerastide in treatment of diabetic foot ulcers. Eur J Pharmacol. 2018;834:77-83. doi:10.1016/j.ejphar.2018.07.014

85. Singh B A safer approach in vaccination-can nanobiotechnology provide solutions to prevent adverse events following immunization by safely and rapidly removing heavy metals in vaccines? Researchgate.net; 2016.

86. Fraga-López F, Rebolo H, Seijas JA, et al. Characterization of nanocomposites using microwaves for curing process; 2016.
Journal of Multidisciplinary Healthcare

\section{Publish your work in this journal}

The Journal of Multidisciplinary Healthcare is an international, peerreviewed open-access journal that aims to represent and publish research in healthcare areas delivered by practitioners of different disciplines. This includes studies and reviews conducted by multidisciplinary teams as well as research which evaluates the results or conduct of such teams or healthcare processes in general. The journal

\section{Dovepress}

covers a very wide range of areas and welcomes submissions from practitioners at all levels, from all over the world. The manuscript management system is completely online and includes a very quick and fair peer-review system. Visit http://www.dovepress.com/testimonials. php to read real quotes from published authors. 